\title{
Streaming from a Diagnostic and Therapeutic Endoscopy Room: It Is Possible at Low Cost
}

\author{
Claudio Navarrete Garcia ${ }^{1,}$, Lazaro Arango $^{2}$, Eduardo Valdivieso ${ }^{3}$, Marcelo Ponce ${ }^{4}$, \\ Cecilia Castillo ${ }^{5}$, Carlos Barrientos ${ }^{6}$, Priscilla Lopez ${ }^{6}$, Arturo Valle ${ }^{6}$, Ignacio Robles ${ }^{6}$, \\ Jaquelina Gobelet ${ }^{7}$, Hugo Incopff ${ }^{8}$, Diego Marutate ${ }^{9}$, Jorge Isaguirre ${ }^{10}$, Jesus Rodriguez ${ }^{11}$, \\ Alvaro Jalal $^{12}$, Pablo Ortiz ${ }^{13}$, Wladimir Estrada ${ }^{13}$, Luis Villota ${ }^{13}$, Carlos Jaramillo ${ }^{14}$, \\ Andres Sanchez ${ }^{14}$, Claudia Diaz ${ }^{14}$, Alberto Angel ${ }^{14}$, Fabian Puentes ${ }^{14}$, Mario Jaramillo ${ }^{14}$, \\ Monica Londoño ${ }^{14}$
}

${ }^{1}$ University of Chile and the Desarrollo, Surgeon and Advanced Endoscopist at the Santa Maria Clinic, LAGETC, Santiago, Chile

${ }^{2}$ Md, FASGE, Advanced Endoscopist, Universidad de Caldas, Union de Cirujanos SAS - Oncologos de occidente, Manizales, Colombia

${ }^{3}$ Advanced Endoscopist, Ildetecsa Endoscopic Therapeutic Center's Chief, Bucaramanga, Colombia

${ }^{4}$ Diagnostic and therapeutic Endoscopy service Sanatorio Argentino, San Juan, Argentina

${ }^{5}$ Endoscopist Surgeon, San Borja's Hospital, Santiago, Chile

${ }^{6}$ Endoscopic Surgery Unit, San Borja's Arriaran Hospital, Santiago, Chile

${ }^{7}$ Gastroenterology and Digestive Endoscopy Service, Sanatorio Allende, Cordoba, Argentina

${ }^{8}$ Unit Specialized in Digestive System, Diagnostic Sanatorium, Santa Fe, Argentina

${ }^{9}$ Endoscopic Surgery Section, Eva Peron's Hospital, Buenos Aires, Argentina

${ }^{10}$ Surgeon and Endoscopist Endoscopy Center Italian Hospital, Mendoza, Argentina

${ }^{11}$ Sabana's University Bogota, North Clinic Barranquilla, Bucaramanga, Colombia

${ }^{12}$ North Clinic Barranquilla, Bucaramanga, Colombia

${ }^{13}$ Fellows Gastroenterology and Surgical Endoscopy, Caldas University, Manizales, Colombia

${ }^{14}$ Surgeons and Endoscopist Union de cirujanos SAS - Oncologos de Occidente Manizales Colombia, Caldas University, Manizales, Colombia

\section{Email address:}

cnavarrete@clinicasantamaria.cl(C. N. Garcia), lazaro.arango.m@gmail.com (L. Arango)

${ }^{*}$ Corresponding author

\section{To cite this article:}

Claudio Navarrete Garcia, Lazaro Arango, Eduardo Valdivieso, Marcelo Ponce, Cecilia Castillo, Carlos Barrientos, Priscilla Lopez, Arturo Valle, Ignacio Robles, Jaquelina Gobelet, Hugo Incopff, Diego Marutate, Jorge Isaguirre, Jesus Rodriguez, Alvaro Jalal, Pablo Ortiz, Wladimir Estrada, Luis Villota, Carlos Jaramillo, Andres Sanchez, Claudia Diaz, Alberto Angel, Fabian Puentes, Mario Jaramillo, Monica Londoño. Streaming from a Diagnostic and Therapeutic Endoscopy Room: It Is Possible at Low Cost. International Journal of Gastroenterology. Vol. 5, No. 1, 2021, pp. 26-32. doi: 10.11648/j.ijg.20210501.14

Received: April 1, 2021; Accepted: April 19, 2021; Published: May 8, 2021

\footnotetext{
Abstract: Background and Aims: Before the covid-19 pandemic, medicine was practice and taught almost entirely face-toface. The new normal, presented us with an opportunity to change the paradigm. Previously, live video transmission was only possible with the use of satellites, that were too expensive to be use regular bases. Now it is possible to broadcast live cases, from anywhere around de world, at a relative low cost. Methodology: This is a descriptive study to show the experience in transmissions of endoscopy live procedures from endoscopy rooms of different centers of Latin America ascribed to the Latin American Training Center (LAGE-TC) adapting virtual transmission technologies for a diagnostic and therapeutic endoscopy, to broadcast cases in real-time through the internet. Results: From April 2020 to July $31^{\text {th }}, 2020$ we have made transmissions every week, for each center, being Tuesdays designated for transmissions from Manizales in Colombia from the Unión de Cirujanos SAS (Dr Lázaro Arango M), Wednesdays from San Borja Arriaran, in Santiago de Chile (fellows training center of Latin America and from where the LAGE-TC is born) (Drs. Claudio Sergio Navarrete Garcia- Cecilia Castillo T, Carlos
} 
Barrientos- Ignacio Robles and Arturo Valle) and from San Juan in Argentina (Dr Marcelo Ponce), on Thursdays from Santa Fé Argentina (Dr. Hugo Imcof), and the Clínica del Norte in Barranquilla - Colombia (Drs. Jesús Rodríguez and Álvaro Jalal). Transmissions have also been made from other centers in Santiago de Chile, Mendoza (Dr Jorge Isaguirre) and Cordoba (Dra Jackelina Gobelet) in Argentina, and in Bucaramanga - Colombia (Dr Eduardo Valdivieso - Fundación Ildetecsa). 23 live broadcasts of cases from all the named cities in Latin America have been made, almost all from one center and being seen by the other centers already named as initial tests. One of the last meetings was held simultaneously between the Latin American Training Center in Santiago de Chile and the Hospital de San Juan in Argentina. The transmissions were done with good quality of video and sound, at a relative low cost. Conclusion: The study shows in detail different ways in which an endoscopy room can be adapted to perform live broadcasts with elements easy to get and at low cost, with good quality images. The adaptation of this technology will allow live transmission of medical classes, conferences with large audience, consultation form experts on line in other units, cities or countries, to improve medical knowledge and care.

Keywords: Endoscopy, Webcast, Education, Medical

\section{Introduction}

Currently, the world is going through an unprecedented crisis derived from the Coronavirus 19 (Covid-19) a pandemic that is dramatically changing the way that medicine is practiced and taught [1]. Before the pandemic, teaching was almost entirely face-to-face, as well as specialist evaluations, consultations, and concepts that required a personal meeting between patient and doctor. Furthermore, conferences and large congresses with large number of attendees, were the spaces used for updates on therapies and technological advancement. However, right now with the new normal given by COVID - 19, we are changing the paradigm. In our area of digestive endoscopy, simultaneous transmission of cases in national and international medical meetings, have been done. Knowing that medical events like conferences will change, even if the pandemic ends, we have taken current learning as a starting point for our development, since social distancing is the new norm. Also, we have been forced to change the way our meetings are conducted, and we have used multiple meeting platforms that have taught us that being together is possible, even in the distance [2].

Technology, virtuality, and the internet are tools that allow us to connect globally and give us the possibility to perform many of the activities previously mentioned only with the use of a computer, video camera, or cell phone. Through these devices, you can issue a medical concept, evaluate diagnostic images, follow up on live procedures, or perform specialized consultations from anywhere in the world [3-5]. In addition, virtual classes, conferences, and web congresses can reach large numbers of people without the need to be gathered in the same place $[2,6]$. This pandemic has led us to something good, and that is the globalization of medical knowledge.

Digestive endoscopy is a diagnostic and therapeutic tool that uses video devices to get images of different organs. These images or videos can be stored in special devices or can be transmitted for therapeutic and academics purposes [7-9]. In recent years, streaming of live cases has been an important part of medical congresses, allowing specialists to show their advances and innovative techniques to a large audience, especially in the area of therapeutic endoscopy, endoscopic ultrasonography (EUS) and endoscopic retrograde cholangiopancreatography (ERCP) [3, 9, 10, 13]. Previously, satellites were the only tool capable of successfully transmit video images to remote sites in real-time, but their costs are very high to be use in regular bases [3]. Currently, the services of Broadband internet allow the transmission of images in realtime with good quality at a low cost. There are different video transmission technologies (Digital Video Transport System, DVTS; H. 323 Video Conferencing Solution; Vidyo), and applications for live transmission or "Streaming" (zoom, Google hangouts, GoToMeeting, Cisco Webex Meetings, YouTube live, Facebook among others) that allow the display of video content at the same time they are being recorded and downloaded [3, 12-14].

The purpose of this article is to present our experience in organizing and implementing a video transmission system in real-time, at low cost, in a diagnostic and therapeutic digestive endoscopy room. The main objective is to use technology to improve health care through virtual consultations and expert advice from anywhere in the world $[3,6,11]$. Also, it aims to facilitate the connectivity and transmission of medical knowledge in times of pandemic, and even after it, by doing virtual classes, webinars, and presenting live cases in national and international conferences for academic purposes [5]. Since we are an academic training center, many times we receive calls of our satellite endoscopy units via Facetime to carry out the visualization of endoscopic images in real-time. Many of our graduates need an opinion of a case and record a video to send it via WhatsApp, or many times use video calls to transmit some images in request for help. This is a useful but difficult system, due to the motility of the cell phone camera, nevertheless, it has been used with pride and has helped doctors and patients a lot. Almost all the platforms that are currently available online, allow us to see colleagues in realtime and interact with them. In those same meetings, we can share the screen of our computer and dictate conferences and show videos. This is leading us to consider for now on, to hold conferences virtually, at a low cost and from our office or home without having to make long trips.

At the time, the Latin American Training Center (LAGE TC) in association with many other groups and entities have hold more than 50 high-quality virtual events, with 
discussion in live cases and new techniques since the beginning of the pandemic. Before, attendance in a conference room was of about 500 attendees maximum in a top conference. Now we can easily reach more than 700 attendees from all over the world using virtual support.

At this event, San Borja's Arriaran team from Chile, directed by Claudio Navarrete García and a group of eager members of the Latin American Training Center, including Drs. Navarrete, Lázaro Arango from Colombia, Eduardo Valdivieso from Colombia, Jesús Rodríguez from Colombia, Marcelo Ponce from Argentina, Jorge Isaguirre from Argentina, Priscilla López from Argentina, Carlos Barrientos from Chile, Arturo Valle from Chile, Ignacio Robles from Chile, Cecilia Castillo from Chile and Hugo Hincof and Diego Mariurate from Argentina, we have each been in the LAGE-TC, testing case-transmission systems based on the conferences that have been implemented virtually. This way, it has been possible to have virtual advice on special cases, where group experts, give their concept on the best use of a technique, or in the resolution in real-time case. Within our group we have units in other cities, and every day since we have started with these virtual transmissions, we have been able to start a live transmission and see cases that they want to comment on, in less than 5 minutes. This way, we have been able to solve difficult cases, make diagnosis in USE, and help in ERCP to achieve a proper stent placement, all in real-time, being several hours away.

\section{Methodology}

This is a descriptive study to show the experience in the LAGE - TC, in the adaptation of virtual transmission technologies for diagnostic and therapeutic endoscopy cases in real-time through the internet, adapting to new normality of COVID - 19. In all the services involved, there is an informed consent that requests authorization from patients and families to produce videos and photos, for academic purposes. The patient's face is not shown in any of the transmissions and if they share data from their medical record, it is done without the patient's name or anything that links him or her directly.

We use the Zoom platform, which is an accessible virtual meeting and video call platform for desktops, laptops, smartphones, and tablets. We acquire the paid version called webinar, which was downloaded directly from their website (http://zoom.us). We based the dynamics of our transmissions on a host, or several hosts as available, plus some panelists and assistants as provided in the platform. The host gets into the ZOOM program and schedules a new event. This scheduling gives you advance features, to generate invitations, either freely available or limited, according to the needs of the streaming. It also allows the cameras and microphones of the assistants to be on or off. This is vitally important to prevent hackers from entering, since we divide the session in a special guest room (where the selected guests of several centers, each has a private link) and the assistants who enter freely with a microphone or camera are unable to use it (they enter the meeting, hear and see the broadcast of those who are interacting, can ask questions by chatting or raising their hand, and at the host discretion, may be temporarily enabled to use the camera and microphone).

We divide the devices assigning each one a role. The person named as the Host has the role of organizing the session. To do this, we choose the computer in the room that receives the signal. Our advanced therapeutic endoscopy room consists of an endoscopy tower, Endosonograph with processor, and a C-arm fluoroscope. As there are many centers involved in the implementation of this work, the brands of the equipment are different. (Figure 1).

At the beginning, we started by making transmissions through video calls with cellphones, but the movements did not allow a proper display of images. The next step was to connect the medical equipment (endoscopy tower and fluoroscopy) to the room's computer (Host).

We use AVer Media DVD EzMaker 7 image capture hardware (Figure 2) and data transmission cables, to transfer images from these devices to a computer. The computer we call Host has a connection to broadband internet, and the zoom application was downloaded. With this, we were able to transmit endoscopic images with good quality in real-time, with the function called: share the screen (Figure 3). As it is common at conferences, we will always have a Panelist 1 who is the main speaker and who intervenes the patient. This panelist will have an assigned cell phone, connected to ZOOM platform, to create and share the link that gives access to the transmission. In the case of Panelist 1, we will only leave the microphone open and turn the camera off. This is done in order to allow the person to speak while doing the case explaining. For this purpose, we have used one of the congress rosettes holders, where the Panelist 1, puts his cell phone and hangs the badge holder around his neck (Figure 4).

A Panelist 2 is assigned, this will be the cell phone that is put into the environment through a tripod. You can also use a Webcam (figure 5). In the same way, this cell phone is given the link of the Zoom meeting, and its camera is on, but the microphone is off so there is no echo in the transmission. There could be another cell phone capturing another environment to which management is given as an equal panelist.

Some fluoroscopes have direct video output and the signal can be passed to a computer, thus sharing the image by zoom as we do with the endoscopy tower. Other Fluoroscopy system has a special adapter which is a DVI VIDEO SPLITTER, which must be ordered directly from the factory. When this device arrives, it is connected to another computer to which a panelist link will be assigned to transmit the X-rays images. Meanwhile, and to our surprise, those without this adapter have adapted a mechanical arm that has a way to carry a cell phone, or a web camera connected to a computer. When using the device, it only focuses on the screen. This cellphone or camera receives the role of a Panelist 3. As the others, it connects to the Zoom conference through a link and is also set with the camera on and the microphone off. The images are very good. (Figure 6). When the meeting is scheduled, it is 
done through the ZOOM platform and the link is sent to all guests. More than 20 transmissions have already been made; the majority between Latin American endoscopy centers and doctors attached to lage-tc, exchanging with other doctors in the care of patients in pandemic; and with graduates of training programs that may be in other cities in America.

It is open to the discretion of the institution the use of a device which can extract the image directly from the C-arm to the computer, or the use of a cellphone or webcam fixed to a $\mathrm{C}$-arm according to the availability in the centers. Both options display an excellent quality of images. (Figure $7 \mathrm{a}$ $7 b)$. It is important to explain the attendees, that they will have several images inside of the screen in their computer or cellphone from which they are watching the transmission, and they must with the mouse or its equivalent, click on the image that they want to see, to make it the main image.

The Whole system can be understood in Figure 8.

\section{Results}

From April 2020 to July $31^{\text {th }}$, 2020, we have made 23 transmissions under the methodology used as follows:

1. 8 transmissions from San Borja Arrarian to Latin America

2. 2 transmissions from San Juan, Argentina to Latin America

3. 1 transmission from Santa Fe, Argentina to Latin America

4. 1 transmission from Córdoba to members of LAGE-TC to interact in a therapeutic procedure

5. 2 transmissions from Barranquilla, Colombia to Latin America

6. 1 transmission of a critical endoscopic surgical case from Fundación Ildetecsa in Bucaramanga, Colombia

7. 1 transmission of simultaneous altered cases from San Borja Arriaran in Chile and San Juan in Argentina.

8. 4 Transmissions from Manizales, Colombia to Chile and Argentina.

9. 3 Transmissions of help to doctors who require it and request an immediate emergency connection to be made.

All transmissions have been made under a paid ZOOM platform, specified before. The videos have a delay between broadcast and display of about 3 seconds, which is imperceptible. The sound quality is excellent if the other microphones in the broadcast room are off, leaving only Panelist 1 active. When we used wireless headphones, the sound was not so good, since it captures a lot of the periphery sound, that is why we advise the use of cable headphones connected to the panelist's cell phone. Therefore, we use the cover of the congress rosette, so that Panelist 1 can hang it from their neck and can transmit their voice smoothly while working.

Xray images look much better with the Logitech Brio $4 \mathrm{~K}$ webcam or cel phone camara, fitted with a pipishell arm 25 inches, especially made for Logitech cameras. We had connectivity problems in some of the meetings, which improved in minutes. This was improved by increasing the internet capacity. When any cell phone in the room has an open microphone, in addition to Panelist 1, generates an echo that makes sound difficult, but that was no longer problem, since we left all the microphones in the room closed (except the one that the panelist 1 uses to explain the cases).

Most of the transmissions were testing meetings. These lasted between 1 and 5 hours. In two of our International broadcasts, we left the ZOOM program open so that each of the observers could enter according to their time availability; and this way, 12 procedures were performed between endoscopies during the diagnostic and therapeutic day, including ERCP and EUS. In one of them, Dr. Claudio Navarrete from Chile completely directed one of the fellows from one of the institutions in the procedure (he, from his center in Santiago de Chile, has directed other specialists in Latin America in the same way). The activity was genuinely nice, because each one could access from their country according to their time availability and could see, learn, and comment. The meetings were held without problems and the objective of guiding the specialist towards the best conduct to perform was accomplished.

\section{Discussion}

Covid-19 has presented us with new challenges in our medical practice and has rapidly changed the way medicine is practiced and medical knowledge is shared. We have reached a new normal. The big congresses with doctors giving conferences to many attendees will continue after the pandemic, but a door to attend virtual conferences is open [15]. The massification of high-speed internet connections, wireless connections, computers, and smartphones, each time at a lower cost, make technology the ideal tool to work in Pandemics. Likewise, to enter new eras, it is necessary to increase teleconsultation in cases of medical controls when the presence of the patient is not necessary. Live video streaming can be done with a cell phone or computer connected to internet, webcams and online platforms at very low costs, unthinkable to be made a few years ago. Currently, almost all medical equipment has digitized images, which allow its capture and transmission on different screens or devices. This makes easier to integrate them into a computer for live transmission over the internet.

In our case, the transmission of images from the devices in the room was done with image capture hardware and data transmission cables, which are easy to get at a low cost. The other tools that facilitate the connection are the web conferencing platforms, which are available for free, or by payment at a relative low cost, compared to the satellite transmission costs that were used in previous times $[3,11]$ In our case, several options were tried to transmit images, such as using cellular devices, using webcams, and direct connections of the equipment. In general, they all worked adequately with good image quality and ease of communication, with the previously mentioned limitations. The least expensive options are the use of phones connected to the zoom platform, but its only and great disadvantage is that these cell phones' battery 
reduces faster when streaming video. The use of cameras web had a better result, and the additional cost was relatively low. These cameras have the advantage that they provide good image quality and do not require additional energy. Their disadvantage is that they do not transmit the images directly from the equipment and may be affected by the movement of the equipment or external lights, also for each web camera we must have an extra computer. Finally, for Xray equipment that allow the option with direct device connections they give a computer the advantage of not being influenced by the light of the room or inadvertent movements. Our transmissions have proven to be useful, excellent in terms of image and sound, and the cost has been minimal. With the live streaming, many people can meet anytime and anywhere in the world, by simply using a connection service on their personal computers or smartphones. Participation can be done from the comfort of their homes or offices or from any other place. Meetings that would otherwise be lost due to lack of time, inability to travel, travel costs, or social confinement can be attended. This leads to incredible savings in economic expenses, time, and organizational costs. Webcasting is a technological tool that provides a great opportunity for medical continued education.

The purpose of this review has been to describe a form of high-quality transmission at a low cost, without incurring in excessive costs to access these possibilities of technology. This article was written in the time of the Covid-19 pandemic, motivated by the need to continue medical education despite limitations in mobility, travel, and social gatherings with crowds of people who appear at congresses or traditional symposia. Progress in endoscopy as in other branches of Medicine requires the dissemination of information on techniques and technology.

\section{Conclusion}

Availability, demand, and the practice of digestive endoscopy pose an increasing challenge in continued education. Hoping that this is spread and shared efficiently, promulgate the art and science of endoscopic techniques and technologies; it is important to face this challenge. For years, self-study, multimedia programs, web publications, and conferences have been used. For some years, an interactive educational mechanism of live broadcast has been explored; initially involving some excessive costs given by the technology available at the time, that included or required sophisticated equipment or technologies, even satellite connection. With the advancement of technology and ease of access, it has opened a myriad of connection possibilities using the internet network, video capturers, hardware and software at a relatively low cost. The study shows in detail different ways in which you can adapt an endoscopy room to perform live broadcasts with easy elements to get good quality images and at a low cost. The options presented can be taken as an example by other institutions to perform streaming.

The objectives achieved are using very economical technology of universal access, achieving teaching sharing and remote collaboration in endoscopic procedures.

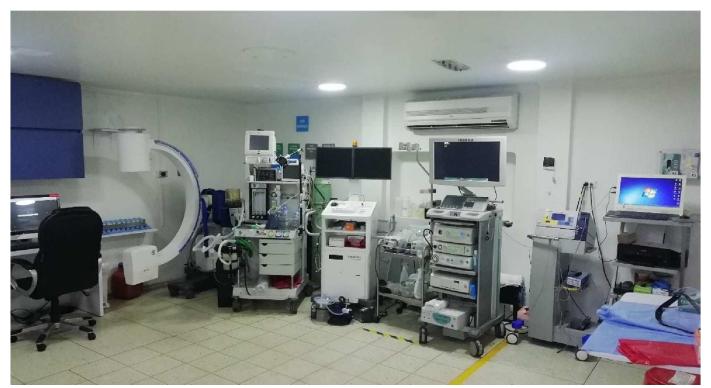

Figure 1. Room, with the Endoscopy tower and the C-Arch.

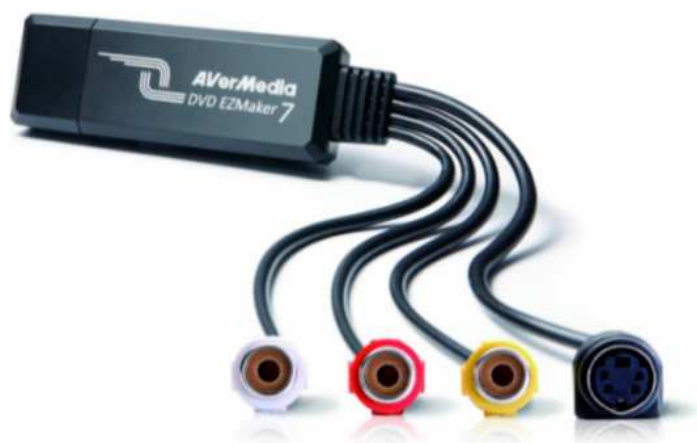

Figure 2. Image capture hardware AVer Media DVD EZMaker 7

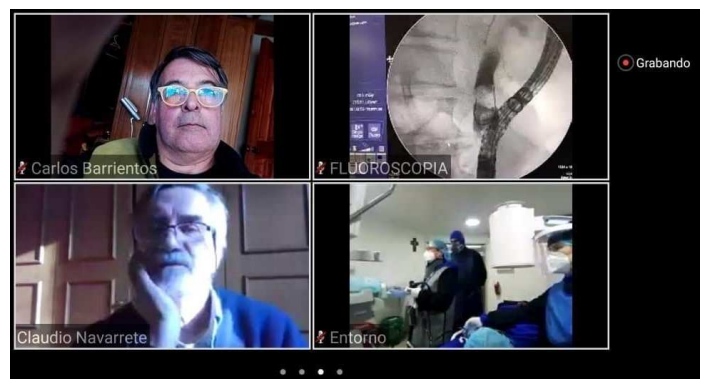

Figure 3. Screen is being shared from the C-Arm with the Logitech webcam connected, to a computer that is inside the ZOOM transmission. Two are seen specialist observers from Chile. Drs. Claudio Navarrete and Carlos Barrientos and one endoscopic room in any place of Latinoamerica shown by panelist 2 which is the cell phone on a tripod that shows the ambient. It can be several cell phones from different places.

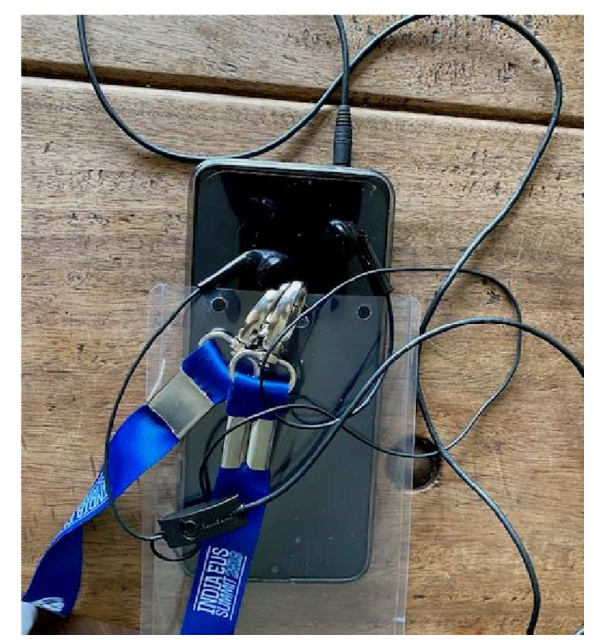

Figure 4. Rosette case to put the cell phone inside. Panelist uses the wired headphones and only sound is e nabled while the camera function is closed. From this cellphone, panelist 1 speaks. 


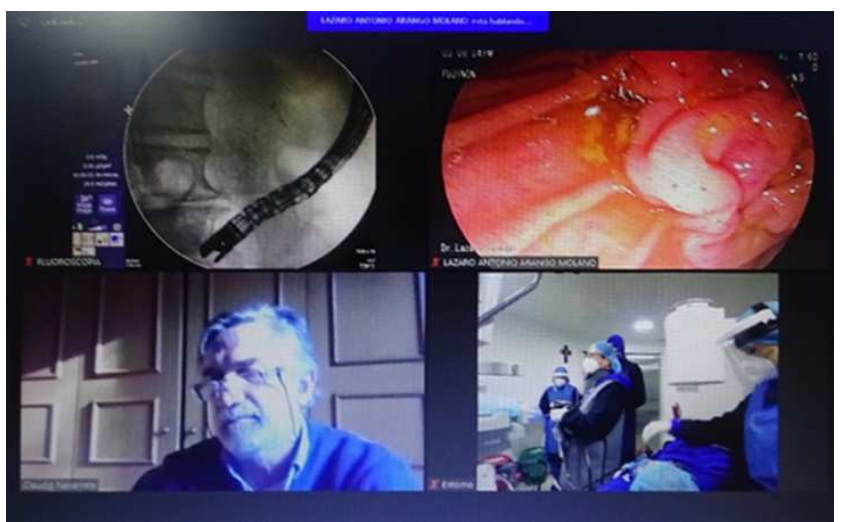

Figure 5. PC vision, It is seen the fluoroscopy vision, the endoscopic vision, the environment vision and one of the assistant in Chile (Dr. Navarrete). The panelist 2, environment transmission through Zoom (Cellphone in tripod). A web cam in the fluoroscopy screen (panelist 3), in this case of webcam use, we must transfer the image to a computer preferably, which we would name as one of the panelists.

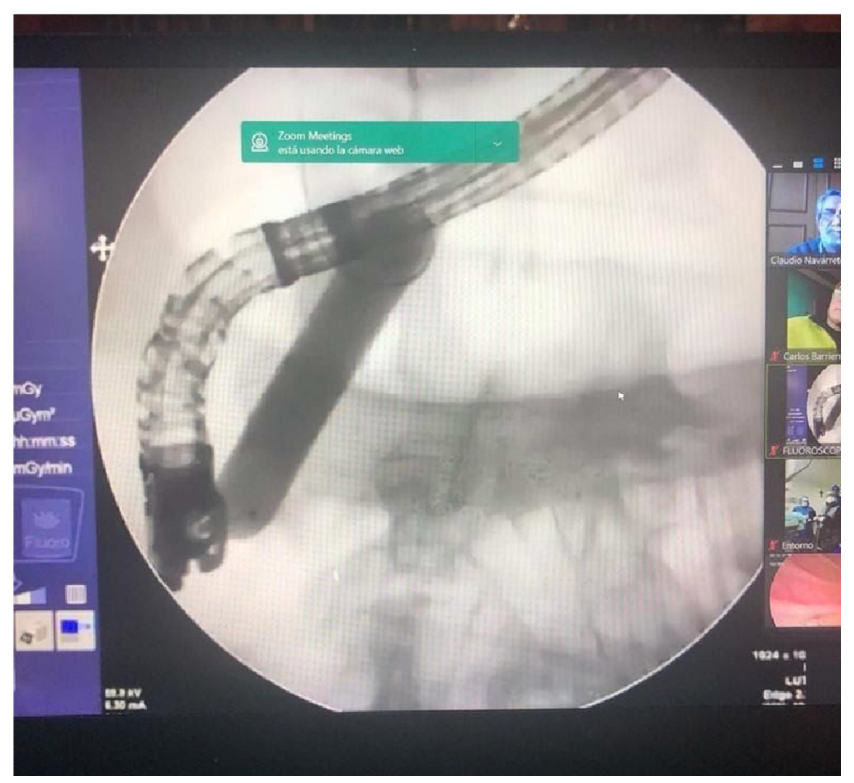

Figure 6. X-ray image in transmission.

The dilatation balloon is seen, dilating a papilla of Vater and on the right side the meeting attendees. The image quality is excellent.
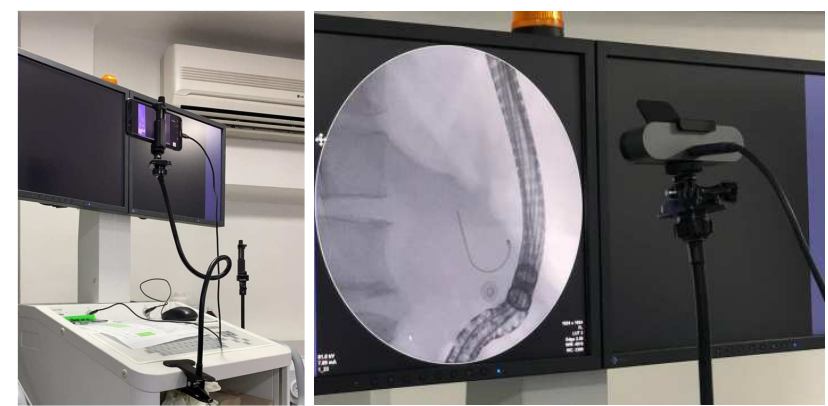

Figure 7. a. Flexible arm that holds a cell phone. b. Flexible arm that holds a web cam in the Fluoroscopy imagen.

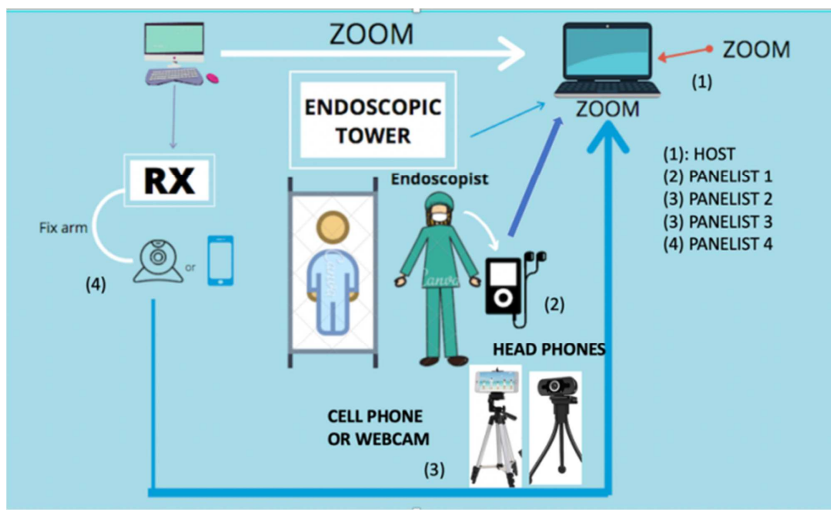

Figure 8. We use a Zoom platform. Everything is connected to each other. The number (1) corresponds to the host, and is the computer where the ZOOM meeting is scheduled. (2) Is the Panelist 1 (Endoscopist) with a Head phones - Open microphone and off the camera. (3) Panelist 2: Environment. (4) Panelist 3, Is Rx, Connected by Cellphone or web cam to ZOOM. The endoscopic tower needs transfer the endoscopic image to the host computer. (The Figure was done by Luna Arango Botero).

\section{Disclosures}

All the authors declare that they have no conflicts of interest.

\section{References}

[1] Culp WC. Coronavirus Disease 2019. A A Pract. 2020; 14 (6): e01218. doi: 10.1213/xaa.0000000000001218.

[2] Zaid I. Almarzooq, MBBCH, Mathew Lopes, MD, Ajar Kochar, MD. Virtual Learning During the COVID-19 Pandemic. A Disruptive Technology in Graduate Medical Education. MAY 26, 2020: 2635-8. doi.org/10.1016/j.jacc.2020.04.015.

[3] Shimizu S, Kudo K, Antoku Y, Hu M, Okamura K, Nakashima N. Ten-year experience of remote medical education in Asia. Telemed J E Health. 2014; 20 (11): 10211026. doi: 10.1089/tmj.2014.0018.

[4] Chaet D, Clearfield R, Sabin JE, Skimming K. Ethical practice in Telehealth and Telemedicine. J Gen Intern Med. 2017; 32 (10): 1136-1140. doi: 10.1007/s11606-017-4082-2.

[5] Augestad KM, Lindsetmo RO. Overcoming distance: Videoconferencing as a clinical and educational tool among surgeons. World J Surg. 2009; 33 (7): 1356-1365. doi: 10.1007/s00268-009-0036-0.

[6] Jarvis-Selinger S, Chan E, Payne R, Plohman K, Ho K. Clinical telehealth across the disciplines: Lessons learned. Telemed e-Health. 2008; 14 (7): 720-725. doi: 10.1089/tmj.2007.0108.

[7] Murad FM, Banerjee S, Barth BA, et al. Image management systems. Gastrointest Endosc. 2014; 79 (1): 15-22. doi: 10.1016/j.gie.2013.07.048.

[8] Rabenstein T, Maiss J, Naegele-Jackson S, et al. Teleendoscopy: Influence of data compression, bandwidth and simulated impairments on the usability of real-time digital video endoscopy transmissions for medical diagnoses. Endoscopy. 2002; 34 (9): 703-710. doi: 10.1055/s-200233568 . 
[9] Kaltenbach T, Muto M, Soetikno R, et al. Teleteaching endoscopy: the feasibility of real-time, uncompressed video transmission by using advanced-network technologies. Gastrointest Endosc. 2009; 70 (5): 1013-1017.e10. doi: 10.1016/j.gie.2009.05.016.

[10] Shimizu S, Itaba S, Yada S, et al. Significance of telemedicine for video image transmission of endoscopic retrograde cholangiopancreatography and endoscopic ultrasonography procedures. J Hepatobiliary Pancreat Sci. 2011; 18 (3): 366374. doi: 10.1007/s00534-010-0351-8.

[11] Parthasarathi R, Gomes RM, Palanivelu PR, et al. First Virtual Live Conference in Healthcare. In: Journal of Laparoendoscopic and Advanced Surgical Techniques. Vol 27. Mary Ann Liebert Inc.; 2017: 722-725. doi: 10.1089/lap.2016.0339.

[12] Ho S-H, Rerknimitr R, Kudo K, et al. Telemedicine for gastrointestinal endoscopy: The Endoscopic Club E- conference in the Asia Pacific Region. Endosc Int Open. 2017; 05 (04): E244-E252. doi: 10.1055/s-0043-102935.

[13] Shimizu S, Ohtsuka T, Takahata S, Nagai E, Nakashima N, Tanaka M. Remote transmission of live endoscopy over the Internet: Report from the 87th Congress of the Japan Gastroenterological Endoscopy Society. Dig Endosc. 2016; 28 (1): 92-97. doi: 10.1111/den.12508.

[14] Minh CD, Shimizu S, Antoku Y, et al. Emerging technologies for telemedicine. Korean J Radiol. 2012; 13 Suppl 1: 21-30. doi: 10.3348/kjr.2012.13.S1.S21.

[15] Yuen J, Xie F. Medical education during the COVID-19 pandemic: perspectives from UK trainees. Postgrad Med J. 2020; 96 (1137): 432-433. doi: 10.1136/postgradmedj-2020137970. 